\title{
You Have the Right to Exclaim Your Pain: Honoring Black Familial Voices Impacted by Police Induced Trauma in the United States
}

\author{
Allen Eugene Lipscomb ${ }^{1}$ \\ Social Work Department, California State University Northridge, USA
}

\begin{abstract}
The impetus of this Black Action Research was to explore the lived experiences of Black families exposed to physical assault, emotional abuse, murder, and racial profiling by law enforcement (i.e. police induced trauma). Narrative qualitative methods were selected to conduct this body of research. The study utilized a Critical Race Theoretical orientation as a framework to honor counter-storytelling in understanding these experiences that often go untold, unheard and unnoticed. A total of 10 narratives were shared of which all resided in Los Angeles County and identified as Black/African American. The results that were found after analyzing the narratives revealed the following emergent themes: (a) aggressive racial profiling that goes unchecked, (b) fear for Black men and boys (c) surviving police encounters via avoidance, and (d) predominant conversation of race throughout one's lifetime. The goal of this article is to speak truth through Black action research methodology in order to bring about recognition, validation and healing.
\end{abstract}

Keywords: Black families, police induced trauma, Narrative methodology, Black action research

"It is not necessary that you believe that the officer who choked Eric Garner set out that day to destroy a body. All you need to understand is that the officer carries with him the power of the American state and the weight of an American legacy, and they necessitate that of the bodies destroyed every year, some wild and disproportionate number of them will be Black."

Between the World and Me

- Ta-Nehisi Coates

\section{Introduction}

Say their names! Charleena Lyles, Shukri Ali, Deborah Danner, Rekia Boyd, Mya Hall Miriam Carey, Aiyana Stanley-Jones, Philando Castile, Freddie Gray, Michael Brown, Eric Garner, Tamir Rice and Alton Sterling to name but a few have all been murdered by law enforcement. Black Americans are overly-represented among those killed by police and law enforcement under all conditions, situations and circumstances. According to the US Census they estimate that Black Americans make up 13\% of the general population in the United States. However, in 2015 the US Census accounted for $26 \%$ of those that were killed by police, in 2016, $24 \%$, and in $2017,23 \%$ of all those killed by police law enforcement (The Guardian, 2016). Thus, Black Americans were the primary targets and victims of the lethal use of force with a firearm or otherwise by police officers at nearly two times the rate of the general population in the United

\footnotetext{
${ }^{1}$ Assistant Professor, Social Work Department, CSUN, Correspondent E-mail: Allen.Lipscomb@gmail.com
} 
States. In addition, it was reported that Black Americans make up $20 \%$ of all people killed by police/law enforcement in the first half of 2018 (Washington Post, 2018).

Thus, leading to the impetus of this study, which was to explore the experiences of Black families exposed to police induced trauma (i.e., physical assault, emotional abuse, murder, and racial profiling) and witnessed the impact on their family. The author utilized what he refers to as Black Action Research - research that strives to honor Black folk living and lived experiences. It seeks to celebrate and highlight unapologetically the uniqueness that is Black community, culture and to promote healing and resiliency. In addition, Critical Race Theory (CRT) is valuable when considering police induced trauma against marginalized and minoritized groups (i.e. African Americans) in a hierarchal society, because it offers a critical understanding that the trauma inflicted against African Americans stems from a larger White supremacy dominant narrative (Aymer, 2016; Chaney \& Robertson, 2013). The author employed CRT as a framework to understand the impact of police induced trauma on the Black family. CRT's five tents are grounded in the importance of recognizing race and racism and their interconnectedness with other forms of subordination throughout institutions and systems, an analysis of dominant belief systems, and commitment to social justice (Chaney \& Robertson, 2013). CRT is used as a framework to understand the impact police-induced trauma has on Black families physically, emotionally, financially, and spiritually. The United States has a long history of police engaging in police brutality against Black folk. The Health and Human Services Office of Minority Health (2015), reported that Black Americans are $20 \%$ more likely to experience mental health issues than the general population. "Exposure to violence increases the risk of developing a mental health condition such as depression, anxiety, and post-traumatic stress disorder. African American children are more likely to be exposed to violence than other children" (HHSOMH, 2015). Thus, the research questions for this study are, 1) What are the lived experiences of African American/Black families with law enforcement who reside in Los Angeles County? How have these experiences with law enforcement impacted African American families (i.e. individually and or collectively) in their day to day life following these encounters?

It is a historical fact that African Americans have experienced oppression and subjugation from enslavement era to the Jim Crow era to the civil rights movement, and now mass incarceration of Black males. African American men, women, and children have suffered physical, psychological, sexual, and emotional trauma throughout each oppressive period (Aymer, 2016; Petersen \& Ward, 2015). A review of the literature suggests that police induced trauma results from racism, racial profiling and officers own unconscious racial biases (Chaney \& Robertson, 2013; Chaney \& Robertson, 2015). The literature on CRT supports the belief that racism is a major factor in the lives of African Americans and helps social workers understand the depth of systematic oppression against African Americans who have been experiencing trauma since chattel enslavement. Policing in African American/Black communities is not a new phenomenon; there are historical roots of over policing evolving from the slavery era in the United States. Before we can truly explore the impact and experiences of law enforcement related abuse on the African American/Black community, it is essential to understand the historical sociopolitical context of policing among African Americans/Blacks within the United States. According to Alpert (2015) Majority of historical data around police relations with African Americans/Blacks in the 20th and 19th century is comprised of narratives and basic records as data around police interactions and use of "force" had not been properly identified nor recorded by the U.S. government until well into the 1960's.

According to Mitchell (2000), "Police brutality is defined as any act of unmerited excessive and aggressive physical, mental, and/or emotional abuse, above and beyond the law, enacted upon by an individual or groups of individuals in law enforcement" (p. 2). This is substantial due to the 
fact that the rate of police killings, especially that of Black men, has drastically increased over the decades. From1999 to 2011, law enforcement officers within the United States reported killing over 4,500 people, 96 percent of which were done with the use of firearms and 96 percent of them men of color (Males, 2014). According to Males (2014), this is referred to as "legal interventions," defined by the Centers for Disease Control and Prevention as "injuries inflicted by the police or other law-enforcing agents . . . in the course of arresting or attempting to arrest lawbreakers, suppressing disturbances, maintaining order, and other legal action" (p. 1).

There is limited known information within the literature about how these violent experiences with law enforcement impacts the African American/Black families well beyond those encounters. Specifically, how do they their psychological health, both as individuals and as a collective family unit within the community. According to Nelson (2001), "Fear, indifference, paranoia, passivity, alienation, and violence are a few of the byproducts of living in a society in which we are the victims of, or silent partners in, abusive, brutal, and racists behavior by the police" (p. 15). Although these experiences are real and present within African American/Black communities by law enforcement, there has been limited focused on exploring the overt lasting psychological impact that these encounters may have on the families. The lack of literature around the familial impact of law enforcement induced trauma on African Americans/Blacks demonstrates an urgency to adding to the research.

\section{Racism in the United States}

Marger (2012) defines racism as, "an ideology, or belief system, designed to justify and rationalize racial and ethnic inequality" (p. 25). Institutional racism relates to social and institutional policies that exclude African Americans from receiving benefits offered to other members of society (e.g., federal drug laws, housing, and education) (Utsey et al., 2000). Both covert and institutional racism continues to play a role throughout policies and practices that are rooted in social structures, systems, and institutions that systematically expose and generate racial inequality (Kolivoski et al., 2014). Researchers have argued that racism is a widespread, aggressive influence on the health of African Americans and other ethnic minorities in the United States (Hummer, 1996; Williams \& Williams-Morris, 2000). It is important as researchers that we explore the experiences of Black families who have been exposed to police induced trauma to see whether or not this has an impact on their health and overall well-being. Why does racism experience have such an impact on Black families?

Plant and Peruche (2005) research suggest that White police officers view Black men as potential perpetrators, which increases the likely hood of police violence. Perceptions of African Americans, particularly Black men, are thought to be aggressive criminals and dangerous (Carbado \& Rock, 2016; Plant \& Peruche, 2005). Therefore, it is not uncommon that police officer's act aggressively towards African Americans as a result of being influenced by race (Carbado \& Rock, 2016; Jefferies et al. 2011). Stereotypes that portray African Americans as violent human beings have been ingrained within America's culture and consciousness that excessive force has become the norm (Carbado \& Rock, 2016). Therefore, the use of force by white police officers against African Americans may be instinctive or internalized, as cognitive or oppressive schemas (Hurtado, 1996). 


\section{Racial Profiling in the United States}

Staples (2011) looks at the history of racial profiling and considers it to be rooted in "white slave-owners" controlling their "so-called property" (p. 32), because in 1693, the city of Philadelphia allowed its police officers to stop any Black person walking on the street to determine whether or not they were free from their slave owner. This is the beginning of racial profiling, officers stopping someone who is Black because they appear out of place. Racial profiling leads to unfounded arrests, mass incarceration, police brutality, and murder (Alexander, 2011; Carbado \& Rock 2016; Chaney \& Robertson, 2015). According to Staples (2011), it is more than the crime that determines whether or not an individual goes to jail, but rather the race and class of an individual. According to Staples (2011), "Arrest rates are three to four times higher for blacks than for whites when black American's are less likely than whites to use drugs, and there is no credible evidence that they sell drugs more often." (p. 34). The mere fact that Blacks are more likely to be arrested for a crime that Whites are doing more often than Blacks is a direct link to racial profiling.

Officers are no longer stopping people from seeing if they are free from their slave owners; however, in New York City officers are allowed to stop-and-frisk a person if they appear suspicious (Staples, 2011). Staples (2011) states, "that more than 80 percent of those stopped and frisked in New York were Black or Latino" (p. 35). Racial Profiling inhibits African Americans from living in a society where they can have a sense of belonging. In 1996, Hilary Clinton spoke to a Keene State University audience and said the following:

We need to take these people on. They are often connected to big drug cartels; they are not just gangs of kids anymore. They are often the kinds of kids that are called super-predators, no conscience, no empathy. We can talk about why they ended up that way, but first, we need to bring them to heel. ("Mrs. Clinton's Campaign Speech", 1996)

When African Americans are described and portrayed as violent, evil, animalistic criminals, it is no surprise that officers target African Americans to do a stop-and-frisk. Fast forward after Mrs. Clinton's speech, America was introduced to mass incarceration, also known as "The New Jim Crow" which was a result of President Bill Clinton's presidency (Alexander, 2011).

\section{Racial Biases in the United States}

The stereotypes of African Americans as violent, criminal human beings are well documented for decades (Carbado \& Rock, 2016; Eberhardt et al., 2004; Sagar et al., 1980). Due to this stereotype, many people believe that African Americans are more likely to be violent than White men; this stereotype lingers in the unconscious mind of officers which causes racially biased "interpretations of suspects' behavior" (Carbado \& Rock, 2016; Plant \& Peruche, 2005). Implicit bias (e.g., racial profiling) and explicit biases (e.g., racism) are alike in the sense that people assign individuals to stereotypes related to their groups (e.g., race, gender, age) and these stereotypes can influence perceptions and behaviors (Fridell \& Lim, 2016). An officer who has an implicit or explicit bias may view an African American as a violent criminal due to the many stereotypes that exist within American society.

According to Plant and Peruche's (2015) study which used a computer simulation program to determine whether or not officers had an unconscious bias towards Black males over White males, it was found that officers were more likely to shoot Black men. An essential element of bias is the human automatic tendency to categorize. Fridell and Lim (2016) write, "People categorize 
individuals and objects to make sense of the world, and this includes categorizing people we don't know ("ambiguous stimuli") according to group membership" (p. 38). People categorize from the time they are born. Babies are trying to find out who is safe and who they can trust. When children get older, they are categorizing the many things they encounter (e.g., dogs, balls, etc.). Before knowing the difference between football and basketball, a child will just say, "I want a ball." Categorizing comes naturally to us, and though stereotypes can be detrimental when forming relationships, or getting pulled over by the police, people continue to do so.

\section{Critical Race Theory and Police Induced Trauma}

Critical Race Theory (CRT) is a useful theoretical approach when studying police induced trauma encountered by Black males. According to Chaney and Robertson (2013) the primary concepts of critical race theory are: "(1) the primacy of race and racism and their interconnectedness with other forms of subordination, (2) a questioning of the dominant belief system/status quo, (3) a commitment to social justice, (4) the centrality of experiential knowledge, and (5) a multidisciplinary perspective" (p. 484). CRT illustrates how race is embedded within institutional structures (i.e., law enforcement). CRT seeks to study and transform the relationship between race, racism, and power, and, questions the fundamentals of liberal order (Abrams \& Moio, 2009; Kolivoski et al., 2014). CRT suggests that racism is so deeply rooted in American society that it is hard to treat and address due to its invisibility (Aymer, 2016; Kolivoski et al., 2014). Racial profiling and racial biases can be understood by using CRT because racism is intricately intertwined in racial oppression which complicates the lives of African Americans in the United States. African Americans are more likely to be stopped and frisked, followed in stores, and CRT can be a useful tool when examining the experiences of Black families exposed to police induced trauma because race, racism, and power are prevalent within the trauma.

\section{Methodology}

Positionality within my Black Action Research. Over the past 12 years working with Black families in community-based mental health agencies (i.e. in Los Angeles and Greater Los Angeles County area) I have seen the impact of police induced trauma. My identity as a Black male therapist and researchers serves as a unique catalyst in positioning myself to in my research to better understand and explore how to increase culturally appropriate Afrocentric and responsive clinical services for Black families. I have spent the past decade learning and receiving clinical training on providing anti-oppressive and affirming treatment to Black families of African descent in the United States. I have studied the psychological effects of trauma and oppression on Black folk. I have collaborated with many Black familial survivors of traumatic grief and loss experiences (i.e. within their family systems and often times within the larger community). It has become my professional quest to serve as a mental health advocate for socially-just clinical services for Black families. It is my promise to honor those voices from all of the Black folk whom I have had the privilege and honor of serving. I recognize both my level of intimacy and connection to this population. Furthermore, I will utilize my academic privileges to ensure full and authentic representation and visibility of my kin-folk in the body of research I contribute.

Research Design. This research study was conducted utilizing qualitative research design, which is useful for developing an in-depth understanding of participants' narratives of their lived experiences (Creswell, 2007; Merriam, 2009). These in-depth narratives provide understanding in 
qualitative research through listening, interpreting, and retelling participants' experiences in a manner that is meaningful and important to them (Crotty, 1998; Denzin \& Lincoln, 2008; Glesne, 2011). In addition, utilizing triangulating, saturation, multiple data sources, and field notes were used. Engaging in qualitative inquiry allows for the trusting relationship of participants and researcher necessary to allow them to feel comfortable sharing and telling their stories in an empowering way by utilizing their voices/narratives rather than numbers, thus allowing the freedom to guide what gets told in order to bring about awareness, justice and change through empirical evidence (Uprety, 2009). Each interview was later transcribed and followed by coding to later identify emergent themes. Open-ended questions were used to allow the participants to share their narratives.

Participants. Participants consisted of $\mathrm{n}=10$ individuals' part of a family unit living in Los Angeles County, California (i.e. 50\% female; and 50\% male). The mean age of participants was 39 years, and all participants identified as Black/African American. Each individual is a parental guardian to at least one child under the age of eighteen.

Permission to recruit participants came from CSUN's IRB. Participants were informed that their responses would remain completely anonymous, and any identifying information will not be disclosed.

Table 1

Participant Demographic Information

\begin{tabular}{cccc}
\hline Gender & Mean Age & Ethnicity & Region \\
\cline { 1 - 2 }$\%$ & Years & & \\
\hline Ma-50\%/Fe-50\% & 39 & African American & Los Angeles County
\end{tabular}

Note. Total Participants $=10$.

Interview questions. Questions asked during the individual interviews emphasized the experiences of Black families exposed to police induced trauma. The following questions were asked in a semi-structured interview: (1) Please describe any personal experiences you may have had with law enforcement throughout your lifetime? How have these experiences shaped you as a person? (2) Looking at what has been going on in the past five years with officer related shootings, murdering unarmed Black men and harassment towards women, discuss the impact this has on your life? (3) Describe how it has impacted your relationships outside of your family (e.g., coworkers, friends, employers)? (4) How has it impacted your family? (5) How is race discussed in your family? (6) How do your children understand race as it relates to them? (7) How is the topic of race different from the time you were growing up until now in your family unit? Or how is it the same? (8) Describe the way your family heals from police violence? (9) Thinking about officers who assault or use racial profiling, describe how you feel about this? (10) What do you think is the solution to police violence?

Procedure. Participants were recruited using a snowball sampling. Participants met with the research team for face to face semi-structured individual interviews. They met at a private location mutually agreed upon by the participants and research team in order to honor comfort and anonymity. The individual interviews consisted of a total of $n=10$ participants. The participants participated in the following activities: (1) Completed a consent form prior to commencing the study (15 minutes) and (2) Engaged in individual interviews (i.e. lasting for 60-75 minutes). 
The individual interviews were audio recorded with the permission of each participant. There was no compensation offered to participants, and no deception was involved in this study. The individual interviews were audio recorded with the authorization of the participants and then transcribed within 72 hours of the interview. The consent forms were stored in a locked box in the locked home of one of the researchers. Audio recordings of the interviews were kept on a password protected computer of the members of the research team. Transcripts of the interviews were deidentified. The interview transcripts were kept in a lockbox separate from consent forms. Only deidentified data was used for analysis. Only the researchers had access to both identifiable and deidentified data.

Data Analysis. In this qualitative research design, the researcher used interviews to collect narratives from participants that experienced police induced trauma either by observation or direct experience. The researchers used a tape recorder to collect interview data from the participants and transcribed, coded, categorized, and identify emerging themes. The qualitative data analysis included identifying and coding patterns that are found in the data collected by interviewing the participants. The researcher team (i.e. graduate social work research students) interviewed 10 individuals between the ages 21-64 who identify as Black/African American. The researcher used a digital recorder to record all interview responses. The researcher used an online dictation program called Transcribe $M e$ to transcribe the participants' interviews. A number was assigned to participants given by the researchers to identify each interview transcription.

The researcher team read through all the data collected to obtain the overall meaning of the participant and to get an in-depth understanding of what was shared. The data gathered from the interviews was transcribed, coded, and categorized into themes. The researcher team identified emerging themes. The researcher team first collected the raw data (transcripts \& field notes), then organized and prepared the transcripts and notes for data analysis by individual participants and read each transcript thoroughly through an iterative process. The researcher used a thematic analysis to analyze the data in order to all for the research team to code and categorize data into themes and then display and classify data according to its similarities and differences within and across the individual participants. After several iterations of reviewing the data efficiently, the research team felt convicted in their ability to highlight and honor the attitudes, feelings, behaviors, actions and beliefs of the participants.

Results. The narratives revealed that majority of the participants (90\%) had an aggressive experience(s) with law enforcement after being racially profiled and pulled over. The narratives also reveal that all participants have a genuine fear that their loved ones may be murdered by an officer, particularly their Black men and young boys. In addition, participants shared that are worried about surviving encounters with law enforcement and are having conversations about surviving being pulled over or stopped by the police. One hundred percent of the participants reported being parents themselves. The following are the four emergent themes found in their narratives.

\section{Theme 1: Aggressive Racial Profiling.}

A prominent theme among each participant was that everyone was pulled over by the police; regardless if traffic laws were not being violated, or crimes were not being committed. Eighty-five percent of the participants were just walking to their car and were stopped by police officers. Two participants (both male and female) were held at gunpoint by an officer, another was 
asked to get out of the car without being asked for identification or vehicle registration, and others were harassed verbally. As one participant recalled a time, they were pulled stated,

We were in Harlem driving back home after picking up some food. All of a sudden, a cop car swerves in front of us, and one pulls up behind us. They draw guns, order us out of the car, and on the ground.

The same participant stated that the officers began to ask them if they had just robbed a bank. Confused, the participant responded to the officer by saying, "What? No, hell no!" They continued by explaining to the officers they were just getting food. Another participant who is a female was also pulled over because she met two of the six physical traits (i.e., African American, and wearing a scarf) of another woman who just robbed an older lady. Participants emphasized that they felt harassed, characterized as a criminal, and anger after being aggressively pulled over by the police.

\section{Theme 2: Fear for Their Black Men/Boys.}

The majority of participants feared more for their male children and male relatives than their female children and relatives. When participants were asked how has recent officer related shootings, murdering unarmed Black men, and harassment towards women, impacted their lives their responses were either living in fear or having feelings of anger. One participant stated,

Now that I am a mother it makes me think of all the things my son is going to go through just because he is African American and he's a male.

There was an emphasis on her child being a male. She continued to state,

It's always a scary feeling whenever his dad leaves the house, or when my son gets older and wants to hang out with his friends, because that's what's going to be in the back of my mind like oh my gosh did my son walk outside with a hoodie on? Did he have earphones in?

One mom has a disabled son and is deaf in one ear she stated,

When my son turns 12, 13, 14, I'm going to constantly be scared for him. I'm going to teach him the right things, but I'm scared since my son is deaf in one ear, he won't be able to respond appropriately to officers." She continued to say, "Cops will think he's disrespectful when he doesn't respond to them because he can't hear them, but he's disabled, and they will mistake that for disrespect" She ended concluded with, "Black men are considered a threat.

\section{Theme 3: Surviving Police Encounters via Avoidance.}

Another reoccurring theme was participants were intentionally avoiding police to avoid being harassed, or possibly shot. Participants are learning to survive police harassment by either deliberately going the other way when they see an officer or overcompensating when they are 
interacting with them by saying things such as-yes sir, no sir, I am reaching for my wallet, sir. One participant stated,

I try to avoid police even though I'm not participating in any crime. As far as I'm concerned being black is considered a crime or driving while black is a crime." Another participant stated, "The way these events have shaped me as a person is to not trust law enforcement." A third participant said, "I still get uneasy when followed by law enforcement even though my driving record is clean as a whistle as well as any criminal history. I am a productive, educated citizen of the United States of America and still get treated like a disregarded peasant with low social status by law enforcement.

Participants talked about their experiences of verbal harassment, and how things with the police and the Black community aren't getting any better. All participants talked about how they are training their kids at a young age on how to interact with the police to ensure that they come home unharmed. Some parents are preparing their children for the day a police officer looks at them as a criminal instead of a human being. As one father said,

Telling my kids, telling myself you have to approach the situation where you can't escalate the situation, you can't be like 'HEY WHY ARE YOU PULLING ME OVER!?' say 'why are you pulling me over?' At the appropriate time...it's a way you interact with the police.

The primary concern of all those who participated in this study was how their children are going to avoid police induced trauma (i.e., verbal and physical harassment, racial profiling, and murder) while living in Los Angeles as an African American. As one mother said,

Unfortunately, it's something you have to teach your kids to make sure they survive.

\section{Theme 4: Predominant Conversation of Race.}

The discussion of police violence is as prevalent in the lives of these participants as they were growing up as it is now that they have children of their own. One participant said,

My children and family coincidently are experiencing the same unfortunate situations the criminal justice system and law enforcement have failed us on.

A more than half of participants explained that what is going on in the news is nothing new for them; the only thing that has changed is that it's being caught on videotape.

\section{Implications of the Present Study}

The findings of this study present several theoretical implications based on themes. Firstly, $100 \%$ of the participants reported being racially profiled, pulled over by the police. Which 
categorically suggest that these encounters are racially motivated. Secondly, all 10 participants reported having at least one negative traumatic experience with law enforcement. Research suggests that African American's, particularly Black men, are generalized as aggressive criminals; therefore, police are more likely to perceive Black men as a threat. In turn, justifying the disproportionate use of deadly force (Chaney \& Robertson, 2013; Plant \& Peruche, 2005).

Thirdly, reflecting upon the four emergent themes - critical race theory is imperative when considering the experiences of Black/African Americans as it related to police induced trauma because it does not ignore the fact that race and racism (from micro to macro) is the strongest indicator for such traumatic experiences. When looking at each theme and examining them through a CRT perspective one can begin to understand why Black/African Americans believe their skin color plays a crucial role when being pulled over and ultimately can die as result of racism and racial bias. To pretend race is not a factor (living color blind), when an officer pulls over a Black man, it normalizes racism and ensures its existence (Abrams \& Moio, 2010). CRT aids us in taking a critical look at how we understand parent fear for their Black men and children and why they must avoid law enforcement or why race is talked about from the time they were growing up to now as adults with their children. Not taking race into account and calling out White supremacy hinders any growth within law enforcement and keeps a divide between police and the Black community (Chaney \& Robertson, 2013). CRT acknowledges the voices in this study, by validating the direct connection between their experiences and race sanctioned practices within law enforcement (James, 2019; Kotluk \& Kocakaya, 2018; LaPaglia, 2018). It is equally important to note that there were several limitations to this research study. First it was a small sample size, and we were limited to Los Angeles County and cannot be generalized to the larger population. That being said, the results of this study can provide insight into the experiences of Black/African American families. Lastly, this research focused on individuals who had a child under the age of 18 living in the home, limiting the diversity in experiences of parents with children who are not under the age of 18 and residing in the home.

To conclude, this study sought to explore and honor the experiences of Black/African American families exposed to police induced trauma. In addition, to contribute to the discussion that is currently taking place in America by addressing what was echoed by Black/African American men and women who participated in this study. Audre Lorde once said, "I have come to believe over and over again that what is most important to me must be spoken, made verbal and shared - even at the risk of having it bruised or misunderstood" (n.d.). Black folks must have spaces to share how this trauma affects their families and how they move day to day in the community. Since there is a public outcry after the epidemic shootings of unarmed Black men and women seen in the United States activist of Black Live Matter will continue seeking solutions and justice for all the families who are survivors of police induced trauma so that Black brothers and sisters' lives were not taken in vain. The goal is that this current study can begin a new approach to the scholarly exploration into the areas of police induced trauma against Black/African American families. Specifically, the study enhances the literature by providing narrative accounts that speak truth to the lasting impact of police induced trauma on the Black/African American families within Los Angeles County. Only when we as a society can listen to the effects of police induced trauma can there be real change. In addition, this study indicates the desperate need for additional exploration of how Black/African American families can heal from these traumatic experiences in an antioppressive culturally congruent manner. This study also suggests further exploration of how activism work, true ally-ship and community advocacy can serve to eradicating police induced trauma. 
"When I dare to be powerful, to use my strength in the service of my vision, then it becomes less and less important whether I am afraid."

Audre Lorde

\section{References}

Abrams, L., \& Moio, J. (2010). Critical race theory and the cultural competence dilemma in social work education. Journal of Social Work Education, 45(2), 245-261.

Alexander, M. (2011). The New Jim Crow. New Press.

Alpert, G. (2015). Police Use of Force. International Encyclopedia of the Social \& Behavioral Sciences (2nd ed.), 18, 255-259. https://doi.org/10.1016/B978-0-08-097086-8.45073-7

Aymer, S. R. (2016). "I can't breathe": A case study-Helping Black men cope with race-related trauma stemming from police killing and brutality. Journal of Human Behavior in the Social Environment, 26(3-4), 367-376.

Carbado, D., \& Rock, P. (2016). What exposes African Americans to police violence? Harvard Civil Rights - Civil Liberties Law Review, 51(1), 159-187.

Chaney, C., \& Robertson, R. (2013). Racism and police brutality in America. Journal of African American Studies, 17(4), 480-505.

Chaney, C., \& Robertson, R. (2015). Armed and dangerous? An examination of fatal shootings of unarmed black people by police. Journal of Pan African Studies, 8(4), 45.

Creswell, J. W. (2007). Qualitative inquiry and research design: Choosing among five approaches ( $3^{\text {rd }}$ ed.). Sage.

Crotty, M. (2004). The foundations of social research: Meaning and perspective. Sage.

Denzin, N., \& Lincoln, Y. (2005). The sage handbook of qualitative research ( $3^{\text {rd }}$ ed.). Sage.

Eberhardt, J., Goff, P., Purdie, V., Davies, P., \& Dovidio, J. (2004). Seeing Black: Race, crime, and visual processing. Journal of Personality \& Social Psychology, 87(6), 876-893.

Fridell, L., \& Lim, H. (2016). Assessing the racial aspects of police force using the implicit- and counter-bias perspectives. Journal of Criminal Justice, 44, 36-48.

Glesne, C. (2011). Becoming qualitative researchers: An introduction $\left(4^{\text {th }}\right.$ ed.). Pearson.

Hummer, R. (1996). Black-White differences in health and mortality. Sociological Quarterly, 37(1), 105-125.

Hurtado, A. (1996). The color of privilege: Three blasphemies on race and feminism. University of Michigan Press.

James, W. Y. (2019). Imprint of Racism: White Adult Males' Transformational Experience from Racial Antipathy to Racial Reconciliation. American Journal of Qualitative Research, 3(1), 93-116. https://doi.org/10.29333/ajqr/5813

Jeffries, J. (2001). Police brutality of Black men and the destruction of the African-American community. The Negro Educational Review, 52(4), 115-130.

Kolivoski, K., Weaver, A., \& Constance-Huggins, M. (2014). Critical race theory: Opportunities for applications in social work practice and policy. Families in Society: The Journal of Contemporary Social Services, 95(4), 269-276.

Kotluk, N., \& Kocakaya, S. (2018). Culturally Relevant/Responsive Education: What do teachers think in Turkey. Journal of Ethnic and Cultural Studies, 5(2), 98-117.

LaPaglia, K. (2018). Book Review: Critical pedagogy: Notes from the real world. American Journal of Qualitative Research, 2(2), 150-153.

Males, M. (2014). Who are police killing? Retrieved from http://www.cjcj.org/news/8113 
Marger, M. (2012). Race and ethnic relations: American and global perspectives (9 ${ }^{\text {th }}$ ed.). Stamford, CT: Wadsworth.

Merriam, S. B. (2009). Qualitative research: A guide to design and implementation. San Francisco, CA: Jossey Bass.

Mitchell, R. (2000). The Student National Medical Association police brutality position statement. Retrieved from http://www.snma.org/_files/live/snma_policy_brutality.pdf

Mrs. Clinton's Campaign Speech. (1996, January 25). https://www.c-span.org/video/?69606$1 /$ mrs-clinton-campaign-speech

Nelson, J. (Ed.). (2001). Police brutality: An anthology. Atlanta, GA: WW Norton \& Company.

Petersen, N., \& Ward, G. (2015). The transmission of historical racial violence. Race \& Justice, 5(2), 114-143.

Plant, E. A., \& Peruche, B. M. (2005). The consequences of race for police officers' responses to criminal suspects. Psychology Science, 16(3), 180-183.

Sagar, H., Schofield, J., \& Manis, M. (1980). Racial and behavioral cues in Black and White children's perceptions of ambiguously aggressive acts. Journal of Personality \& Social Psychology, 39(4), 590-598.

Staples, R. (2011). White power, Black crime and racial politics. The Black Scholar, 41(4), 31-41.

The Guardian. (2016, August). People killed by the police in the U.S. Retrieved from https://www.theguardian.com/us-news/series/counted-us-police-killings

United States Department of Health and Human Services Office of Minority Health. 2015. Available at: http://minorityhealth.hhs.gov/omh/browse.aspx?lvl=2\&lvlid=1.

Uprety, L. (2009). Qualitative Research by Denzin, N.K. and Lincoln, Y. 2005. Nepalese Journal of Qualitative Research Methods, 1, 64-67.

Utsey, S., Ponterotto, J., Reynolds, A., \& Cancelli, A. (2000). Racial discrimination, coping, life satisfaction, and self-esteem among African Americans. Journal of Counseling \& Development, 78(1), 72-80.

Washington Post. (2018). Database of Police Killings; 2018. Retrieved from Available from: https://www.washingtonpost.com/graphics/national/police-shootings

Williams, D., \& Williams-Morris, R. (2000). Racism and mental health: The African American experience. Ethnicity \& Health, 5(3-4), 243-268. 